\title{
THE SMAP LEVEL 4 CARBON PRODUCT FOR MONITORING TERRESTRIAL ECOSYSTEM-ATMOSPHERE CO EXCHANGE
}

\author{
L. A. Jones ${ }^{1}$, J. S. Kimball ${ }^{1}$, N. Madani ${ }^{1}$, R. H. Reichle ${ }^{2}$, J. Glassy $^{1}$, J. Ardizzone $^{2}$ \\ ${ }^{1}$ Numerical Terradynamic Simulation Group, College of Forestry \& Conservation, University of \\ Montana, Missoula, MT, USA \\ ${ }^{2}$ Global Modeling and Assimilation Office, NASA/GSFC, Greenbelt, MD, USA
}

\begin{abstract}
The NASA Soil Moisture Active Passive (SMAP) mission Level 4 Carbon (L4_C) product provides model estimates of Net Ecosystem $\mathrm{CO}_{2}$ exchange (NEE) incorporating SMAP soil moisture information as a primary driver. The L4_C product provides NEE, computed as total respiration less gross photosynthesis, at a daily time step and approximate 14-day latency posted to a 9-km global grid summarized by plant functional type. The L4_C product includes component carbon fluxes, surface soil organic carbon stocks, underlying environmental constraints, and detailed uncertainty metrics. The L4_C model is driven by the SMAP Level 4 Soil Moisture (L4_SM) data assimilation product, with additional inputs from the Goddard Earth Observing System, Version 5 (GEOS-5) weather analysis and Moderate Resolution Imaging Spectroradiometer (MODIS) satellite data. The L4_C data record extends from March 2015 to present with ongoing production. Initial comparisons against global $\mathrm{CO}_{2}$ eddy flux tower measurements, satellite Solar Induced Canopy Florescence (SIF) and other independent observation benchmarks show favorable L4_C performance and accuracy, capturing the dynamic biosphere response to recent weather anomalies and demonstrating the value of SMAP observations for monitoring of global terrestrial water and carbon cycle linkages.
\end{abstract}

Index Terms - Soil moisture, carbon cycle, SMAP

\section{INTRODUCTION}

Following its January 31, 2015 launch, the NASA Soil Moisture Active and Passive (SMAP) mission [1] began acquiring L-band (1.4 GHz) microwave observations of the global land surface at approximate mean 3-day intervals following in-orbit checkout and initial sensor calibration. SMAP brightness temperature $(\mathrm{Tb})$ retrievals and other observational data are assimilated within the NASA Goddard Earth Observing System, Version 5 (GEOS-5) Catchment land surface model to produce daily surface and root zone soil moisture and temperature estimates as part of the SMAP Level 4 Soil Moisture (L4_SM) product [2].

A major SMAP science goal is to improve understanding of linkages between the global water and carbon cycles. To this end, the SMAP Level 4 Carbon (L4_C) product incorporates L4_SM information, with additional daily meteorological inputs from GEOS-5 and land cover classification and 8-day canopy FPAR (canopy absorbed fraction of photosynthetically active radiation) observations from MODIS (Moderate Resolution Imaging Spectroradiometer) to provide detailed estimates of terrestrial carbon fluxes and underlying environmental controls on a global daily basis [3]. Here we evaluate the first year of L4_C production, including detailed product comparisons against a range of independent observational benchmarks, including global tower eddy covariance network based carbon $\left(\mathrm{CO}_{2}\right)$ flux observations and satellite Solar Induced Canopy Florescence (SIF) observations. The product results are also checked against recent documented regional weather and climate anomalies.

\section{L4_C PRODUCT AND ALGORITHM}

The L4_C product provides global terrestrial Net Ecosystem $\mathrm{CO}_{2}$ exchange (NEE) computed as total respiration (vegetation plus soil) less vegetation gross primary production (GPP), on a daily timestep with 14-day latency posted to a 9-km global grid summarized for up to eight major plant functional types defined by an ancillary MODIS global land cover classification. The L4_C product includes additional estimates of NEE component fluxes for GPP and respiration, surface soil organic carbon (SOC) stocks, underlying environmental constraints to these processes, and detailed uncertainty metrics. The L4_C model uses lightuse-efficiency plant production and soil organic matter decomposition logic simplified from the CASA and CENTURY models, relating carbon cycle components to basic meteorological conditions and vegetation-ecosystem functional characteristics [4]. The SMAP L4_SM product provides required driving surface and root-zone soil moisture and temperature data, with additional daily meteorological fields from GEOS-5 to define environmental 
constraints to GPP, respiration and decomposition processes, including combined impacts from sub-optimal daily soil moisture levels, excessive atmosphere vapor pressure deficits, frozen conditions and low minimum daily air temperatures. The model FPAR inputs are qualitycontrolled and gap-filled using a long-term 8-day FPAR climatology derived from the MODIS era record (20012013). The L4_C model was calibrated using a global network of flux tower sites with multi-year data records, relatively consistent processing and well characterized accuracy, and representing the major global biomes. The L4_C model was initialized to pre-launch conditions by spinning up the model SOC pools to dynamic steady state conditions using GEOS-5 SMAP Nature Run (version 4) soil moisture and surface meteorological inputs from 20012013.

SMAP L4_C validated-version data are publically available through the National Snow and Ice Data Center (NSIDC; http://nsidc.org/data/smap) for the period from March 31, 2015 to present.

\section{FLUX TOWER EVALUATION}

L4_C global NEE accuracy requirements specify an unbiased Root Mean Square Error (ubRMSE) of $\leq 1.6 \mathrm{~g} \mathrm{C}$ $\mathrm{m}^{-2} \mathrm{~d}^{-1}$ which amounts to $\leq 30 \mathrm{~g} \mathrm{C} \mathrm{m}^{-2} \mathrm{y}^{-1}$ on an annual basis over northern $\left(\geq 45^{\circ} \mathrm{N}\right)$ land areas. This accuracy threshold is within the uncertainty level of in situ tower eddy covariance carbon flux observations - the primary data against which L4_C is calibrated and validated [5]. L4_C uncertainty estimates indicate that the targeted annual accuracy threshold is met for $83 \%$ and $66 \%$ of northern and global domains, respectively (Fig. 1a). Comparison with typical seasonal conditions for 228 flux tower locations indicate that the specified NEE accuracy level is satisfied for five of seven global land cover types (Fig. 1b).

The NEE ubRMSE tends to scale proportionally with total carbon flux magnitude, which partially explains higher ubRMSE levels for relatively more productive vegetation types, including Deciduous Broadleaf Forest (DBF), Cereal Crops (CCRP), and Broadleaf Crop (BCRP) types. Product uncertainty also occurs from sub-grid scale $(<1 \mathrm{~km})$ spatial heterogeneity, including close proximity of agricultural fields, woodlots, and pasture within a single cropland vegetation class. Overall, the L4_C NEE performance is within a $30 \%$ relative error accuracy threshold for approximately $82 \%$ of the global domain, where relative error is defined as the proportion of ubRMSE to the total estimated carbon flux (GPP + total respiration).

\section{RECENT SYNTHESIS RESULTS}

Additional L4_C assessments included comparisons against other available benchmarks, including alternative GPP datasets, satellite-based Solar Infrared Florescence (SIF) observations, and soil organic carbon inventories. The
L4_C sensitivity to documented weather anomalies provided another important check on L4_C performance.

Since GPP strongly controls NEE, available independent information on GPP provides a useful check on L4_C performance. We compared L4_C GPP outputs to NASA EOS MODIS MOD17 and Max Plank Institute (MPI) regression-tree-derived GPP products [6,7]. The GPP results were also compared against satellite SIF retrievals from GOME-2 and OCO-2 sensors [8,9], where SIF is used as an observational proxy for vegetation productivity.

The L4_C GPP correlates skillfully with the SIF observations (Fig. 2a). The zonal average $\mathrm{R}^{2}$ correspondence of L4_C GPP versus SIF is 0.84 and 0.88 for GOME-2 and OCO-2, respectively (Fig. 2b). The SIF correspondence with L4_C GPP is also higher than the MOD17 (0.74 and $0 . \overline{7} 6$ for GOME-2 and OCO-2, respectively) or MPI (0.77 and 0.87$)$ results. Since L4_C, MOD17, and MPI all share similar calibration data and, for MOD17 some elements of model logic, it is likely that the higher correspondence between L4_C and SIF may be attributable to the improved soil moisture information from SMAP. Despite these encouraging initial results, more analysis will be required to isolate the added benefit of SMAP data.

Soil organic carbon (SOC) storage inventories provide another useful indirect constraint on NEE. We compared the initialized L4_C surface $(<10 \mathrm{~cm}$ depth) SOC stock estimates with IGBP-DIS global and NCSCD regional inventory-based SOC datasets [10,11]. The SOC results indicate L4_C dynamics broadly consistent with observed SOC inventory records, although with significant deviations for some areas and vegetation classes. The L4_C SOC estimates tend to correlate consistently for grassland, shrubland, and cereal crops indicating favorable L4_C performance in moisture-limited regions. The L4_C SOC estimates deviate from the inventories in forests, especially in the northern latitudes where the SOC inventories are generally higher than the L4_C results. Boreal and Arctic soils have high characteristic SOC levels that have accumulated over thousands years under cold climate conditions, which may not be adequately represented by recent satellite and climate records used for L4_C initialization. The SOC inventory records are also more uncertain in these remote areas due to very sparse measurement networks. Additional L4_C regional assessments are underway that include enhanced information from regional field experiments.

The initial year of SMAP operations encompassed a range of global weather and climate anomalies, which are represented in the L4_C outputs. In North America, an ongoing exceptional California drought decreased estimated summer GPP leading to weakened NEE $\mathrm{CO}_{2}$ uptake. A relatively early spring in the Pacific Northwest coincided with early greenup (increasing $\mathrm{NEE} \mathrm{CO}_{2}$ uptake), which quickly transitioned to lower than average NEE uptake under hot, dry summer conditions. Anomalous rainfall 
across Oklahoma and Texas from May and June thunderstorms enhanced NEE $\mathrm{CO}_{2}$ uptake throughout that region before drier conditions returned. Because the L4_C model accounts for the impact of multiple drivers, offsetting dynamics of moisture and temperature conditions can be investigated. For example: earlier spring may lead to early greenup where enhanced plant growth increases NEE $\mathrm{CO}_{2}$ uptake, but may be offset by warmer conditions which increase respiration. Our results indicate that the L4_C product is sensitive to dynamic weather events and climate anomalies, and gives meaningful diagnostic information on how plant uptake and soil decomposition processes contribute to NEE.

\section{OUTLOOK}

The baseline L4_C model was designed to use land surface freeze-thaw (FT) information at $3-\mathrm{km}$ spatial resolution from SMAP radar observations to define frozen constraints to water mobility and GPP. However, following the loss of the SMAP radar in July 2015, the L4_C model framework was modified to accommodate alternative FT inputs derived using GEOS-5 daily surface temperature and a simple $0.0^{\circ} \mathrm{C}$ threshold to delineate frozen and thawed conditions. The results presented here were derived using relatively coarse (9-km resolution) GEOS-5 temperature based FT inputs rather than finer scale (3-km resolution) FT inputs from the SMAP L-band radar. Planning is underway to incorporate SMAP radiometer based FT information in the $\mathrm{L} 4 \mathrm{C}$ model calculations as these data become available. Model impacts from alternative SMAP and GEOS-5 based FT inputs will also be evaluated. Model FT sensitivity is expected to be greater within complex terrain and land cover areas, during seasonal transitions and within northern $\left(\geq 45^{\circ} \mathrm{N}\right)$ land areas and higher elevations where the frozen season is a larger portion of the annual cycle [12].

The consensus of direct tower validation (Section 3 ) and indirect comparisons with other datasets (Section 4) show promising initial results for L4_C. Further evaluation of the continuing data record will elucidate the impact of SMAP observations for improving NEE estimates and documenting the spatial and temporal dynamics and interplay between the global terrestrial water and carbon cycles. Validated L4_C products are currently available from NSIDC, with further accuracy improvements expected from continuing SMAP calibration improvements and product refinements.

\section{REFERENCES}

[1] D. Entekhabi, and Coauthors, "The Soil Moisture Active and Passive (SMAP) Mission," Proceedings of the IEEE, 98, 704-716, doi:10.1109/JPROC.2010.2043918, 2010.

[2] R. H. Reichle, and Coauthors, "Soil Moisture Active Passive (SMAP) Project Assessment Report for the Beta-Release L4 SM Data Product," NASA Technical Report Series on Global Modeling and Data Assimilation, NASA/TM-2015-104606, Vol. 40, National Aeronautics and Space Administration, Goddard Space Flight Center, Greenbelt, Maryland, USA, 63pp, 2015. Available at: http://gmao.gsfc.nasa.gov/pubs/.

[3] J. S. Kimball and Coauthors, "SMAP Algorithm Theoretical Basis Document, Release A: L4 Carbon Product," SMAP Project, JPL D-66484, Jet Propulsion Laboratory, Pasadena, CA, 76 pp. 2014 Available at: http://smap-archive.jpl.nasa.gov/files/smap2 /L4_C_RevA.pdf.

[4] J. S. Kimball and Coauthors, "A Satellite Approach to estimate land-atmosphere CO2 exchange for Boreal and Arctic Biomes," IEEE Trans. Geosci. Rem. Sens., 47 (2), pp 569-587. 2009. doi:10.1109/TGRS.2008.2003248.

[5] D. Baldocchi. "Breathing of the terrestrial biosphere: lessons learned from a global network of carbon dioxide flux measurement systems." Austr. J. Bot., 56, pp. 1-26. 2008.

[6] M. Zhao and S. W. Running, "Drought-induced reduction in global terrestrial net primary production from 2000 to 2009," Science. 329, 5994, pp 940-943. 2010.

[7] M. Jung and Coauthors, "Global patterns of land-atmosphere fluxes of carbon dioxide, latent heat, and sensible heat derived from eddy covariance, satellite, and meteorological observations," J. Geophys. Res. Biogeosci., 116, G3, DOI:10.1029

/2010JG001566. 2010.

[8] J. L. Joiner and Coauthors, "Global monitoring of terrestrial chlorophyll fluorescence from moderate-spectral-resolution nearinfrared satellite measurements: methodology, simulations, and application to GOME-2," Atmos. Meas. Tech. 6, pp 22803-3823. 2013.

[9] C. Frankenberg and Coauthors, "Prospects for chlorophyll fluorescence remote sensing from the Orbiting Carbon Observatory-2," Rem. Sens. Environ., 147, 5, pp 1-12. 2014. doi:10.1016/j.rse.2014.02.007

[10] Global Soil Data Task Group. Global Gridded Surfaces of Selected Soil Characteristics (International Geosphere-Biosphere Programme - Data and Information System). Oak Ridge National Laboratory Distributed Active. Archive Center, Oak Ridge, Tennessee, U.S.A. 2000. Available at: http://www.daac.ornl.gov

[11] G. J. Hugelius, and Coauthors. Estimated stocks of circumpolar permafrost carbon with quantified uncertainty ranges and identified data gaps. Biogeosciences 11, pp. 6573-6593. 2014.

[12] J. Du, and Coauthors. Classification of Alaska spring thaw characteristics using satellite L-band radar remote sensing. IEEE Trans. Geosci. Rem. Sens., 53 (1), pp 542-556. 2014. 


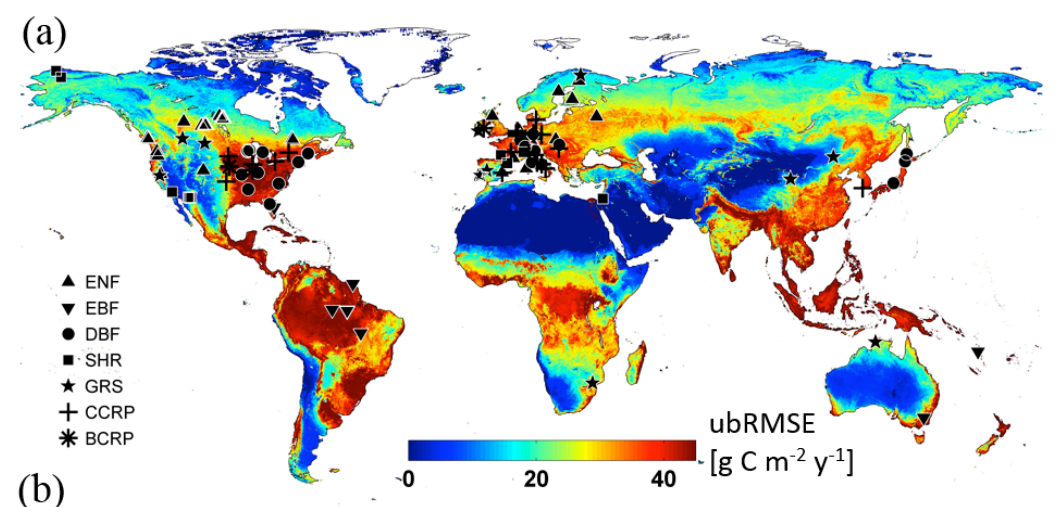

(b)

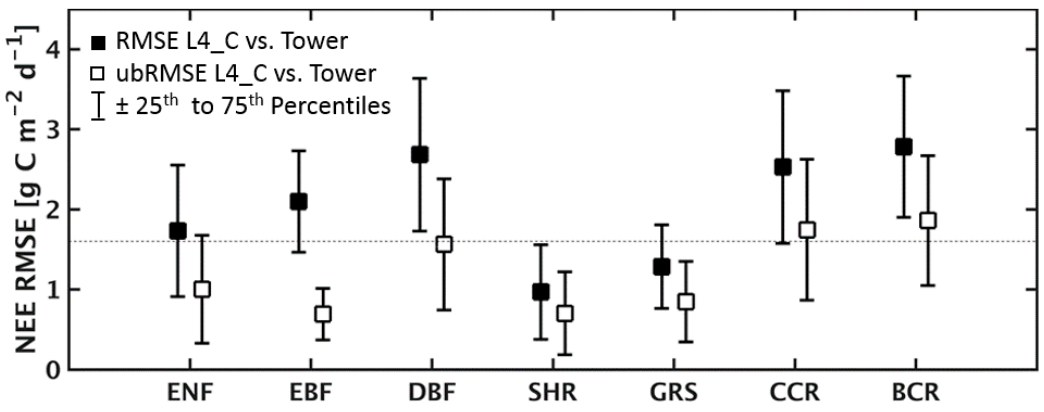

Figure 1: L4_C error summary; (a) L4_C estimated annual ubRMSE for NEE overlain with 228 global flux tower sites used for model calibration and validation, and delineated by land cover type. (b) Summary of daily average RMSE and ubRMSE for tower locations grouped by landcover class for the initial (Apr-Nov) operational product period. Symbols indicate median values for each landcover class with $25^{\text {th }}$ and $75^{\text {th }}$ percentile whiskers. Dashed line indicates L4_C target accuracy of $1.6 \mathrm{~g} \mathrm{C} \mathrm{m}^{-2} d^{-1}$. Landcover key: ENF = Evergreen Needleleaf Forest; EBF = Evergreen Broadleaf Forest; DBF = Deciduous Broadleaf Forest; $S H R=$ Shrubland; GRS = Grassland; $C C R=$ Cereal Crops; $B C R=$ Broadleaf Crops .

(a)

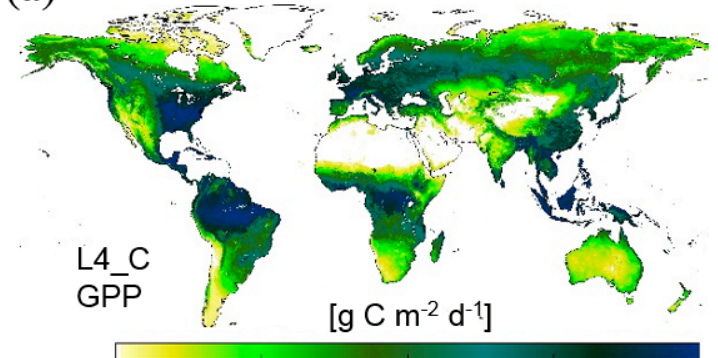

(b)

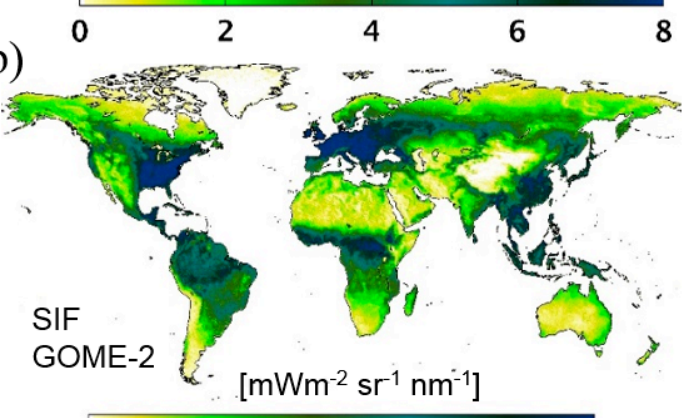

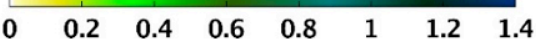

(c)

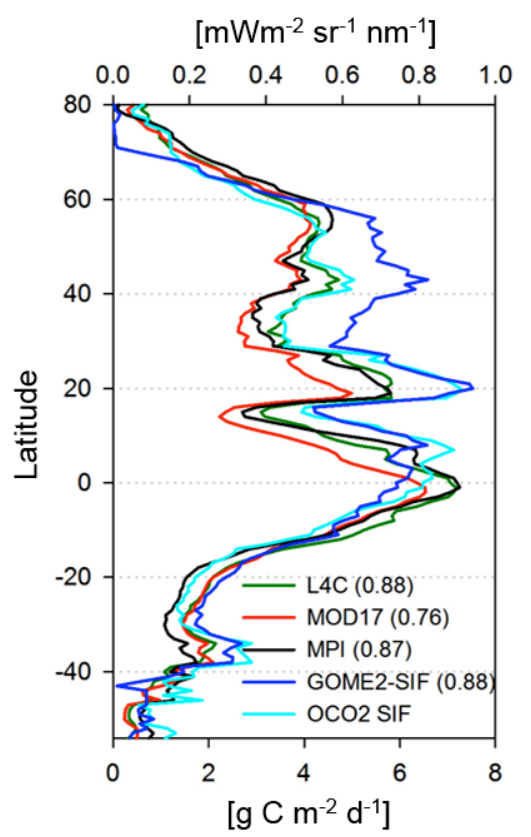

Figure 2: Average daily (a) L4_C GPP and (b) GOME-2 SIF for the period April 13-July 31, 2015. (c) Zonal average plots of mean GPP $\left(\mathrm{gC} \mathrm{m}^{-2} \mathrm{~d}^{-1}\right)$ and SIF $\left(\mathrm{mWm}^{-2} \mathrm{sr}^{-1} \mathrm{~nm}^{-1}\right)$ for the May - September period for L4_C, GOME-2 and OCO-2 (2015), MOD17 (GPP climatology from 2000-2014 record), and MPI (GPP climatology from 2000-2011 record); correlations $\left(R^{2}\right)$ are given for each dataset $v$ s. OCO-2 SIF. 